\title{
Dispersing Carbon Nanotubes in Phenolic Resin using an Aqueous Solution
}

\author{
Edson C. Botelho, ${ }^{*, a, b}$ Elilton R. Edwards, ${ }^{a}$ Birgit Bittmann $^{b}$ and Thomas Burkhart ${ }^{b}$ \\ ${ }^{a}$ Departamento de Materiais e Tecnologia, Universidade Estadual de São Paulo, \\ 12516-410 Guaratinguetá-SP, Brazil \\ ${ }^{b}$ Institut für Verbundwerkstoffe GmbH, 67663 Kaiserslautern, Germany
}

\begin{abstract}
A capacidade de controlar a dispersão de nanotubos de carbono (CNT) em polímeros é considerada ponto chave para a maioria das aplicações de compósitos de nanotubo/polímero. A dispersão de nanotubos de carbono em água com diferentes surfactantes, assim como sua incorporação em resinas fenólicas, foi investigada. Ultrasonicação de suspenções líquidas foi usada para preparar dispersões estáveis. A fim de se avaliar o melhor surfactante a ser usado, espalhamento de luz e espectroscopia UV-Visível foram empregados. A estrutura de CNT reforçada de resina fenólica foi analisada em função da concentração e tipo de surfactante, potência e tempo de sonicação. A influência da dispersão pelo uso das propriedades de transição de temperatura vítrea também foi avaliada, sendo obtida por análise mecânica dinâmica e energia de impacto.
\end{abstract}

The ability to control the carbon nanotube (CNT) dispersion in polymers is considered the key to most applications of nanotube/polymer composites. The carbon nanotube dispersion into water with different surfactants, as well as its incorporation into phenolic resins, was investigated. Ultrasonication of liquid suspensions was used to prepare stable dispersions. In order to evaluate the best surfactant to be used, light scattering and UV-Visible spectroscopy were employed. The structure of CNT reinforced of phenolic resin was analyzed in function of the concentration and type of surfactant, sonication power and time. It was also evaluated the influence in the dispersion by using the glass temperature transition properties being obtained by dynamic mechanical analyses and impact energy.

Keywords: carbon nanotubes, polymeric composites, phenolic resin

\section{Introduction}

Polymer composites based on carbon nanotubes (CNTs) have attracted tremendous attention during these last years due to the impressive mechanical properties of CNTs, including high modulus value (around 1TPa), strength of 50-200 GPa, failure strain of up to $15 \%$ and electrical conductivity ranging from semiconducting to metallic, depending on their structure. ${ }^{1-5}$

The interaction between functional groups of the compatibilizer and carboxyl or amine groups of multi wall carbon nanotubes (MWCNTs) stabilized the morphology and improved the interfacial interaction between MWCNTs and the thermoset matrix. ${ }^{6,7}$ In general, the nanoscale dispersion of MWCNTs in polymeric matrix is achieved by strong hydrogen bonding between hydroxyl groups of the MWCNTs and polymer groups. Therefore, despite the

*e-mail: ebotelho@pq.cnpq.br extremely high strength of individual CNT shells, the weak shear interactions between adjacent shells and tubes lead to significant reductions in the effective strength of multi-walled carbon nanotubes. ${ }^{8-12}$ This is responsible for the carbon nanotube bundles down to only a few $\mathrm{GPa}^{8-12}$

Nowadays, phenolic resins are indeed irreplaceable materials for selective high-technology applications, offering high reliability under severe conditions. Because of its excellent ablative properties, structural integrity, thermal stability and solvent resistance, phenolic resins are still widely used, especially in thermal insulation materials, molding compounds, coatings and composite materials. ${ }^{13-15}$

Our most important goal is the nanotube dispersion control by adjusting the $\mathrm{CNT} /$ phenolic resin interface. However, due to the strong van der Waals forces of single CNTs, this reinforcement tends to form bundles within production process. For thermoset resin, several works have been done ${ }^{7-12}$ in order to deagglomerate CNT bundles using organic and inorganic surfactants solvents. 
MWCNTs can be dispersed into water using surfactants, preferentially those ones with a relatively high HLB (hydrophilic-lyphophilic balance). This non-covalent method is straightforward and is classically applied to disperse both organic and inorganic particles in aqueous solutions. The nature of surfactant, its concentration and type of interaction are known to play a crucial role in the phase behavior of classical colloids as well as CNTs. ${ }^{16-19}$

The use of surfactant is important in order to separate individual nanotubes from the bundles itself within water phase, maximizing the effect of the intrinsic mechanical and electrical properties of CNTs. In case of polymer composites, it is essential to use well dispersed CNTs into water, for instance, to be incorporated into polymer matrix. The surfactant molecules will also potentially serve as the chemical link between nanotubes and matrix itself, providing stronger hydrophobic interactions at the interphase of single CNTs and polymer matrix. It has been proposed that CNTs are either encapsulated in a cylindrical micelle, or are coated by hemimicelles. But, so far, the exact mechanism has not been described in detail. ${ }^{20-23}$

In particular, surfactants such as sodium dodecyl sulfate (SDS) have been studied due to their excellent nanotube stabilization and separation capabilities. ${ }^{22-26}$ In order to find a good surfactant able to resist to high temperature, many other surfactants have been studied. ${ }^{22-26}$ Besides the right surfactant, the technical equipment to be used is also of great importance. It was found that the use of ultrasonication treatment of aqueous dispersions may help to debundle nanotubes by providing high local shear, particularly to the nanotube ends. The stability and quality of an aqueous dispersion can be analyzed by UVVisible spectroscopy and the sedimentation behavior under centrifugation forces has been studied by light scattering techniques. ${ }^{27,28}$

In the present study, to stabilize CNT dispersion into water, two different surfactants (sodium 4-styrenesulfonate (PSSS) and SDS) were used. The respective CNT dispersions were mixed with phenolic resin and cured under vacuum. Light scattering, UV-Vis spectroscopy, scanning electron microscopy (SEM), dynamic mechanical analysis (DMA) and impact energy studies were used in order to characterize the respective CNT-composites.

\section{Experimental}

\section{Chemicals and materials}

The MWCNTs (Baytubes, C150 P) used in this investigation were supplied by Bayer Company (Germany). They are characterized by an average outer diameter of
15-20 nm, number of walls of 3-15 and bulk density of $140-160 \mathrm{~kg} \mathrm{~m}^{-3}$. The manufacturer indicates that the CNTs contain less than 5\% impurities, including residual catalyst. For the production of CNT dispersions, two different surfactants, which were supplied by Sigma-Aldrich, were used: PSSS and SDS. Both surfactants are anionic.

Eponol 2485 phenolic resin was supplied by Hexion Company (Germany). This resin presents as main characteristics, solid content around $66 \mathrm{wt} . \%$, viscosity of 2000-3000 mPa s and ca. 18 min gel time at $100{ }^{\circ} \mathrm{C}$.

\section{Dispersion and characterization of CNT}

The dispersion of MWCNTs with surfactants into water was carried out with a high intensity ultrasonic horn (20 kHz, Branson PG). The vessel of the mixture was cooled in an ice water bath. A good dispersion was obtained after only $1 \mathrm{~min}$.

To evaluate the dispersion quality, dynamic light scattering was applied. The Nanotrac DLS Particle Size Analyzer with a laser Diode of $780 \mathrm{~nm}$ and $3 \mathrm{~mW}$ from Microtrac Inc (USA) was used for this. $\mathrm{X}_{50}$ value of the volume distribution was displayed. $\mathrm{X}_{50}$ value means that $50 \mathrm{vol} . \%$ of the particles in the mixture are smaller or equal to the displayed value.

UV-Visible absorption spectra were recorded with a Hewlett-Packard 8453 spectrometer operating between 200 and $800 \mathrm{~nm}$. Specimens were taken regularly during the sonication and diluted by a certain factor, resulting in certain MWCNT contents that were suitable for UV-Vis measurements. The original surfactant solution diluted by the same factor and after having passed by the same conditions as the ones for CNT dispersions was used as reference material.

\section{Preparation and characterization of phenolic resin - CNT} composites

In order to produce CNT composites, phenolic resin with MWCNT was processed using a mechanical mixer set up at speed of $2000 \mathrm{rpm}$ for $30 \mathrm{~min}$. After this process step, the phenolic resin with MWCNT and water was submitted to dry process using a distillation process $\left(70{ }^{\circ} \mathrm{C}\right.$ under vacuum during $3 \mathrm{~h}$ ). The moisture content was evaluated by using Karl Fisher technique. Since the original moisture content of neat phenolic resin was around $2.5 \%$, this process was done until to be found this value of moisture. After this, the dried phenolic resin with MWCNT was cured into an oven according to the following curing cycle: $80{ }^{\circ} \mathrm{C}$ for $4 \mathrm{~h}, 100{ }^{\circ} \mathrm{C}$ for $4 \mathrm{~h}, 110^{\circ} \mathrm{C}$ for $2 \mathrm{~h}, 120^{\circ} \mathrm{C}$ for $2 \mathrm{~h}, 160^{\circ} \mathrm{C}$ for $1 \mathrm{~h}$ and $200{ }^{\circ} \mathrm{C}$ for $30 \mathrm{~min}$. 
The resulted composite strands were fractured and the surface was analyzed by scanning electron microscopy (SEM) using a LEO 435 (Carl-Zeiss AG Oberkochen, Germany).

The specimens were also cut into $4 \mathrm{~mm}$ thick, $10 \mathrm{~mm}$ wide and $50 \mathrm{~mm}$ length and were tested in an equipment of dynamic mechanical analysis (DMA) from Seiko using a tension clamp at a frequency of $1 \mathrm{~Hz}$ from 10 to $250{ }^{\circ} \mathrm{C}$ with a heating rate of $2{ }^{\circ} \mathrm{C} \mathrm{min}^{-1}$. From these tests, the glass temperature transitions $\left(\mathrm{T}_{\mathrm{g}}\right)$ were estimated by using the maximum of $\tan \delta$ value.

Room temperature notched Charpy impact tests were performed using a pendulum testing machine CEAST according to the DIN-ISO179/1eU standard. Samples with rectangular dimensions were fractured at room temperature by a swinging hammer with impact energy of $4 \mathrm{~J}$ and an impact speed of $2.9 \mathrm{~m} \mathrm{~s}^{-1}$. The distance between sample supports was set to $62 \mathrm{~mm}$.

\section{Results and Discussion}

\section{Effect of sonication time on the dispersion quality of the CNT dispersions}

In order to obtain optimum processing conditions, the influence of the ultrasonic parameters on the particle size was evaluated. The particle diameter runs through a minimum with progressive dispersion time, the smallest particle size was obtained after around $35 \mathrm{~min}$ under sonication (Figure 1). From this figure, it was observed MWCNT agglomeration, tubular entities with thickness on the micrometric range, as also observed in the literature. ${ }^{29}$ The effects of the sonication strength can result in breaking of the tubes. This process can also be monitored by light scattering, in which small values (generally when is found nanometric length of dispersed CNT) is correlated to breaking of the nanotubes. Therefore, in order to avoid this, it was used low power during the sonication process.

To disperse nanotubes into water, surfactant molecules orient themselves in such a way that hydrophilic tail groups build up a bridge to aqueous phase. This process is favorable when the adequate sonication time and power are used. Thus, the dispersing power of the respective surfactant depends on the balance of the respective exchange force between nanotubes/surfactant. Generally, the hydrophobic backbones of the surfactant interchange very well with the CNT graphitic structure because the graphitic unit cells match very well with the methylene units of hydrocarbon chains. So, the efficiency of the adsorption and, consequently, the dispersing power of
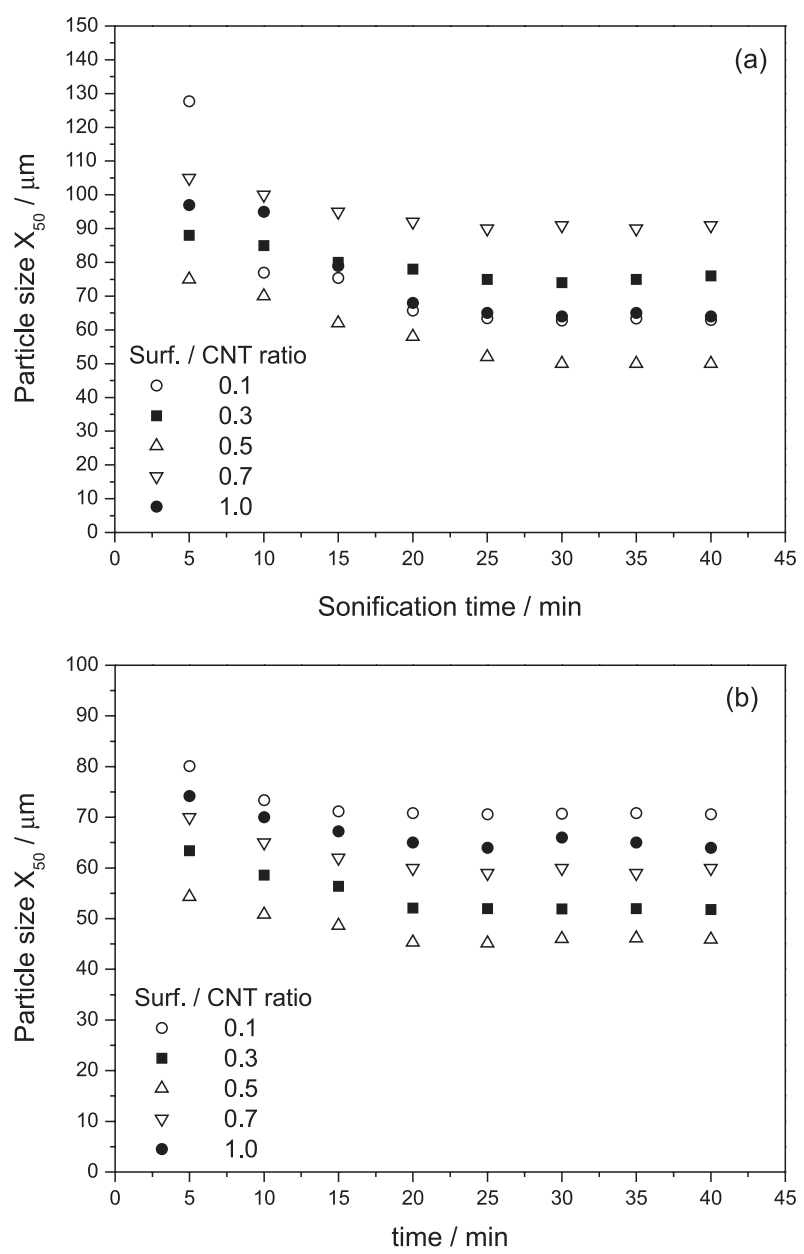

Figure 1. Light scattering results for $0.1 \mathrm{wt}$ \% CNT after using different sonication times in: (a) SDS and (b) PSSS surfactants (both with different surfactant/CNT weight ratio).

surfactants are greatly affected by the backbone length, as well as the kind of sp-hybridization of the carbon atoms of the used surfactant molecules. Additionally, a longer backbone goes along with a higher spatial volume and more steric hindrance, thus providing greater repulsive forces between individual surfactant-loaded carbon nanotubes.

In order to confirm the light scattering results, UV-Vis technique was also used. Figure 2 illustrates UV-Vis spectra of MWCNT-surfactant solutions with different grades of surfactants and after different sonication times. Figure 2 presents the spectra for $0.1 \mathrm{wt} . \%$ CNT with weight ratio surfactant/CNT of 0.5:1 as a function of sonication time and type of surfactant. It is evident that after sonication, the absorbance of MWCNT solutions shows a maximum between 200 and $300 \mathrm{~nm}$ and gradually decreases from UV to near-IR. Similar results have been reported by the literature. ${ }^{6-11}$

Individual CNTs are active in the UV-Vis region and exhibit characteristic bands. However, bundled CNTs are hardly active in the wavelength region between 200 and 

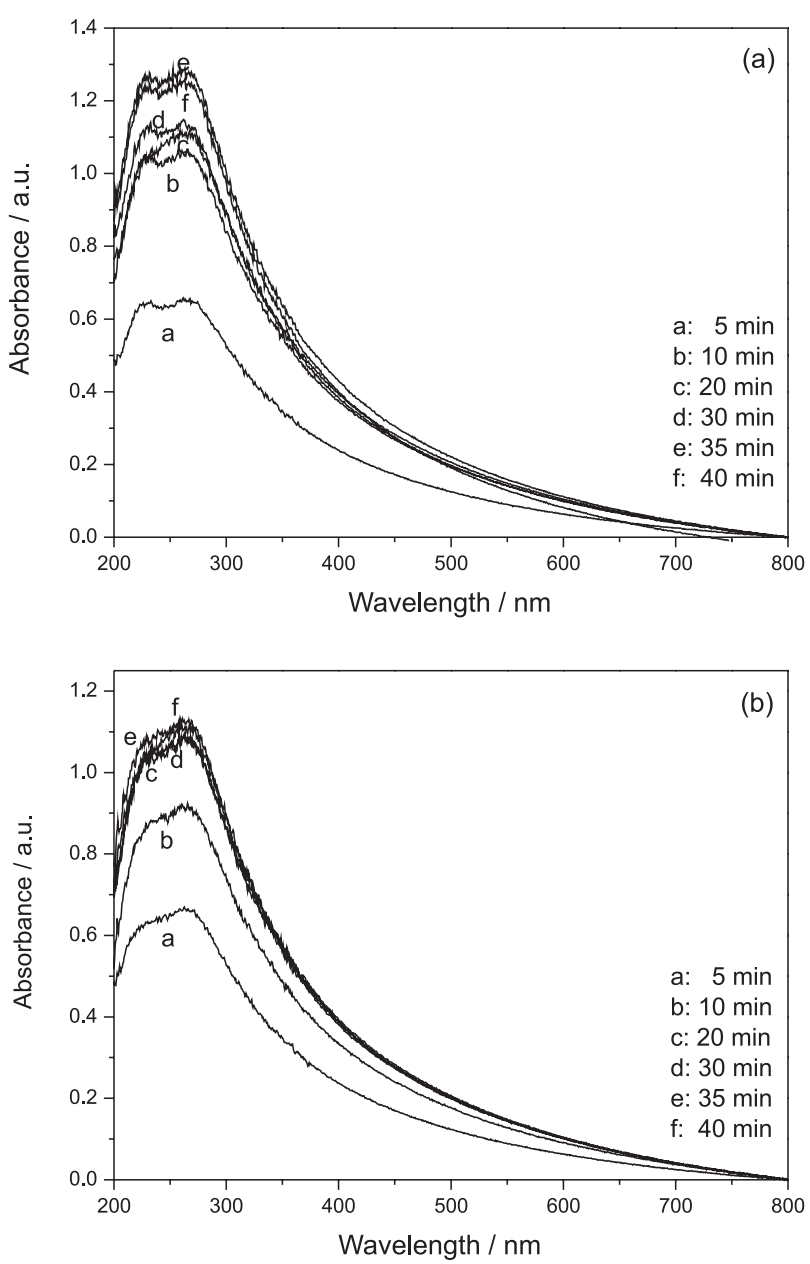

Figure 2. UV-Vis spectra for $0.1 \mathrm{wt} . \% \mathrm{CNT}$ and $0.05 \mathrm{wt}$.\% surfactant as a function of sonication time in: (a) PSSS and (b) SDS surfactants.

$800 \mathrm{~nm}$ most probably due to charge transfer via tunneling between the respective nanotubes. Therefore, it is possible to establish a relationship between the amounts of CNTs individually dispersed into solution and the intensity of the corresponding absorption spectrum. Moreover, UV-Vis spectroscopy can be used to monitor the dynamics of this CNTs dispersion process, allowing the determination of the optimal sonication time.

At the beginning of sonication, there are a lot of big MWCNT aggregates and bundles in solution which are strongly entangled preventing the application of UV-Vis spectroscopy. During the sonication, the provided energy can indeed overcome the van der Waals interactions in the
MWCNT bundles, leading to their disentanglement and dispersion. The increasing amount of dispersed MWCNTs results in an increasing area below the spectrum lines, representing the absorbance. According to these results, the sonication after $35 \mathrm{~min}$ does not contribute anymore to the degree of CNT dispersion into water.

Table 1 shows the degree of dispersion quality by light scattering technique by using PSSS surfactant with different molecular weight and as a function of sonication time. As can be observed, PSSS surfactant with higher molecular weight improves the CNT dispersion quality. This behavior can be explained as a consequence of higher surface activity originated by the higher concentration of benzene rings along the surfactant backbone. The $\Pi$ stacking interactions of the benzene rings with CNT graphitic structure are believed to increase the absorption ratio of the surfactants, as well as of other highly aromatic molecules and rigid conjugated polymers. ${ }^{18-22}$

Investigation of the efficiency and stability of surfactant dispersions with CNT

In order to determine the optimum ratio between CNT and surfactant for each type of surfactant, a second set of experiments was carried out varying the surfactant concentration and keeping constant the MWCNT amount (0.5 wt.\% CNT).

During this work, it could be concluded that the stability of these dispersions is maintained for several weeks, independent of sonication time and concentration of PSSS surfactant. According to this work, it was also evident that the best weight ratio between the MWCNTs and surfactants was 2 (weight ratio surfactant/CNT of 0.5:1). This observation can be explained by the micelle formation with the help of surfactants. At high concentrations, the surfactant molecules form micelles in solution. The increase of the size of these micelles is kept with the increase of the surfactant concentration due to interaction between groups of the same polarity.

\section{CNT dispersion as a function of its concentration}

Figure 3 shows the influence of CNT weight contents on the particle sizes according to the PSSS and SDS surfactants

Table 1. Influence of molecular weight of PSSS surfactant on particle average size ( $\mu \mathrm{m})$ (weight ratio surfactant:CNT of 0.5:1)

\begin{tabular}{|c|c|c|c|c|c|c|c|c|}
\hline $\begin{array}{l}\text { Molecular weight / } \\
\left(\mathrm{g} \mathrm{mol}^{-1}\right)\end{array}$ & $5 \mathrm{~min}$ & $10 \mathrm{~min}$ & $15 \mathrm{~min}$ & $20 \mathrm{~min}$ & $25 \mathrm{~min}$ & $30 \mathrm{~min}$ & $35 \mathrm{~min}$ & $40 \mathrm{~min}$ \\
\hline ca. $250,000.00$ & $68.3 \pm 3.2$ & $63.8 \pm 4.7$ & $60.1 \pm 3.5$ & $59.4 \pm 3.8$ & $56.6 \pm 3.6$ & $58.7 \pm 3.2$ & $57.8 \pm 1.9$ & $57.9 \pm 2.3$ \\
\hline $1,000,000.00$ & $55.4 \pm 3.8$ & $50.5 \pm 3.1$ & $49.8 \pm 4.2$ & $48.9 \pm 2.8$ & $46.1 \pm 1.9$ & $45.7 \pm 1.8$ & $47.0 \pm 2.2$ & $46.8 \pm 2.1$ \\
\hline
\end{tabular}




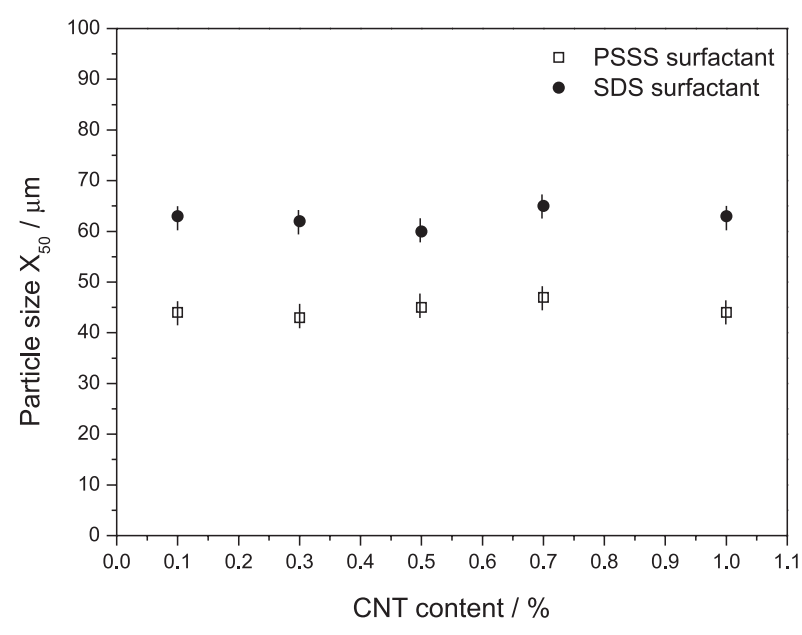

Figure 3. The influence of CNT weight content on the particle size according to the PSSS and SDS surfactants (weight ratio surfactant/CNT of $0.5: 1$ and sonication time of $35 \mathrm{~min}$ ).

(weight ratio surfactant/CNT of $0.5: 1$ and sonication time of $35 \mathrm{~min}$ ). For the respective light scattering analyses, the absolute amount of MWCNTs was identical. The light scattering results up to $1.0 \mathrm{wt} . \%$ of reinforcement are very similar for the different concentrations of MWCNTs.

However, when MWCNT concentration reaches 1.5\%, the sonication does not result in efficient dispersions, not even after very long sonication time, or corresponding sonication energy. ${ }^{15-18}$ Such behavior can be presumably described as a reduction of electrostatic repulsion forces between MWCNTs due to the formation of too many SDS micelles in aqueous solution. The osmotic pressure of micelles around the MWCNT bundles creates an effective attraction, resulting in the depletion-induced aggregation of MWCNTs.

\section{Evaluation of CNT dispersion into phenolic resin}

In order to examine the CNT dispersion into phenolic resin matrices, SEM was applied in fractured surface of $\mathrm{CNT} /$ phenolic resin composites. At high magnification, the individual CNTs can be clearly detected in different regions. It is obvious that tubes are irregularly curved, and some of them are significantly agglomerated in the submicro-scale. Figure 4a-c shows the main results obtained by SEM technique for phenolic resin reinforced with 0.5 wt. \% CNTs, which were processed by the addition of SDS-stabilized CNT. At global dispersion, heterogeneous distribution was found for the processing with $0.1 \mathrm{wt} . \%$ SDS surfactant. On the other hand, relatively homogeneous distributions of CNTs were observed in phenolic resin with 0.5 and $1.0 \mathrm{wt} . \%$ SDS surfactant loadings, but still with some CNT agglomerates in both cases.
Figure 4d-f shows the main results obtained by SEM technique for phenolic resin with $0.5 \mathrm{wt} . \% \mathrm{CNT}$ dispersed with different PSSS surfactant concentrations. In this case, it was also observed a relatively homogeneous distribution of CNTs, but also with some CNT agglomerations (mainly in the specimens with $0.1 \mathrm{wt} . \%$ of PSSS surfactant). This confirms the UV-Vis and light scattering results.

In order to understand the effect of the mixing technique on the mechanical behavior of the nanoreinforced composites, investigations of the CNT distribution using different CNT wt.\% fractions were also carried out. In this case, the use of both surfactants resulted in composites with the same morphology. It is evident from Figure 5 that CNT is effectively dispersed when CNT dispersions with appropriate surfactant concentrations (> $0.1 \mathrm{wt} . \%)$ are used and only a few small clusters (less than $2 \mathrm{~nm}$ ) are observed. The aggregation of the resultant MWCNT of the use of $0.1 \mathrm{wt} . \%$ amount and the milling and mixing processes may restrain the enhancement of the mechanical properties of the composites.

Table 2 presents the glass transition temperature $\left(\mathrm{T}_{\mathrm{g}}\right)$ and also the impact energy results for all studied specimens in this work. The impact energy results offered an improved effect of the nanotubes on the impact behavior for all tested volume loadings. This reinforcement seemed to be already effective at low filler contents (only $0.1 \mathrm{wt} . \% \mathrm{CNT}$ ) and reached the highest level for the present series at $1.0 \mathrm{wt} . \%$ CNT. Unreinforced phenolic resins can be considered as brittle materials and exhibit a high sensitivity to notches, micro-cracks and local inhomogeneities. The reason for this is that notches act as stress concentrators and much of the sample deformation on impact takes place in the vicinity of the notch tip (where a higher apparent strain rate occurs in comparison with unnotched specimens). Therefore, the similar behavior was observed when it was evaluated specimens using PSSS and SDS surfactants (Table 2). When considering the standard deviation, the found impact energy values were the same, also when was evaluated specimens with different ratio of surfactant/CNT.

Similar behavior happened in glass transition temperature when compared to the discussion about impact energy. Also in this case, it was found a similar value when compared specimens obtained from PSSS and SDS surfactants. In this case, the CNT-filled specimens (in all conditions) exhibited lower glass transition temperature $\left(\mathrm{T}_{\mathrm{g}}\right)$ regardless of the rigidity of the nanotubes. This is a strong indication of less curing of the nanostructured composites compared to the neat resin. The viscosity increase caused by nanotubes inclusion was also noticeable during mixing, suggesting a physical hindrance of the carbon nanotubes. This leads to significantly lower curing degrees. Similar 

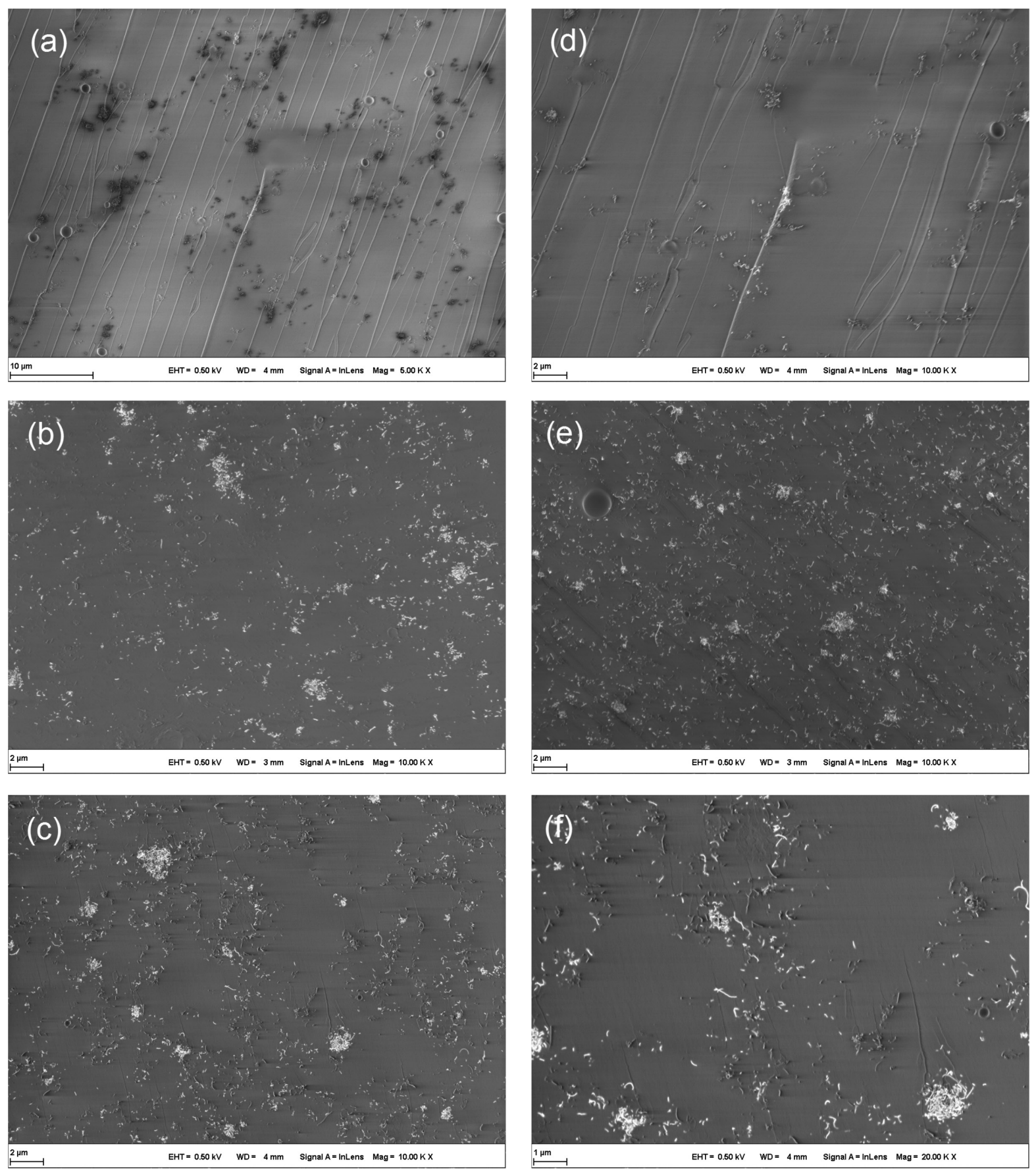

Figure 4. SEM micrographs obtained for fractured surfaces of CNT/phenolic resin composites containing 0.5 wt. $\%$ CNTs: (a) 0.1 wt. $\%$ of SDS, (b) 0.5 wt. $\%$ of SDS (c) $1.0 \mathrm{wt} . \%$ of SDS, (d) $0.1 \mathrm{wt} . \%$ of PSSS, (e) $0.5 \mathrm{wt} . \%$ of PSSS and (f) $1.0 \mathrm{wt} . \%$ of PSSS.

results have been presented by the literature. ${ }^{30}$ Indeed, the thermal properties variation are consequence of several factors, including agglomeration.

\section{Conclusions}

It was demonstrated that the CNT dispersion technique using an appropriate concentration of surfactant can be used to produce $\mathrm{CNT} /$ phenolic resin composites with good carbon nanotube dispersion quality. In this work, it is shown that the MWCNT dispersion in water was achieved by using a high power tip sonication. The CNT dispersion remained stable at least for 4 months and neither sedimentation nor aggregations of nanotubes bundles were observed. During sonication, MWCNTs are gradually disentangled from aggregates and bundles and stabilized by both used surfactants.

From the practical point of view, the use of surfactant was optimized by determining the minimum needed to disperse 
Table 2. Glass transition temperature $\left(\mathrm{T}_{\mathrm{g}}\right)$ and impact energy variation with CNT content (weight ratio surfactant:CNT of 0.5:1)

\begin{tabular}{|c|c|c|c|c|}
\hline \multirow{2}{*}{ wt.\% CNT } & \multicolumn{2}{|c|}{$\mathrm{T}_{\mathrm{g}} /{ }^{\circ} \mathrm{C}$} & \multicolumn{2}{|c|}{ Impact energy / $\left(\mathrm{kJ} \mathrm{m}^{-2}\right)$} \\
\hline & PSSS & SDS & PSSS & SDS \\
\hline 0 & $115.47 \pm 3.23$ & $115.47 \pm 4.31$ & $0.36 \pm 0.01$ & $0.36 \pm 0.01$ \\
\hline 0.1 & $94.61 \pm 1.93$ & $95.87 \pm 2.21$ & $0.40 \pm 0.01$ & $0.39 \pm 0.02$ \\
\hline 0.5 & $93.6 \pm 1.12$ & $93.8 \pm 2.11$ & $0.41 \pm 0.02$ & $0.40 \pm 0.01$ \\
\hline 1.0 & $91.2 \pm 1.76$ & $91.7 \pm 2.08$ & $0.42 \pm 0.02$ & $0.41 \pm 0.02$ \\
\hline
\end{tabular}
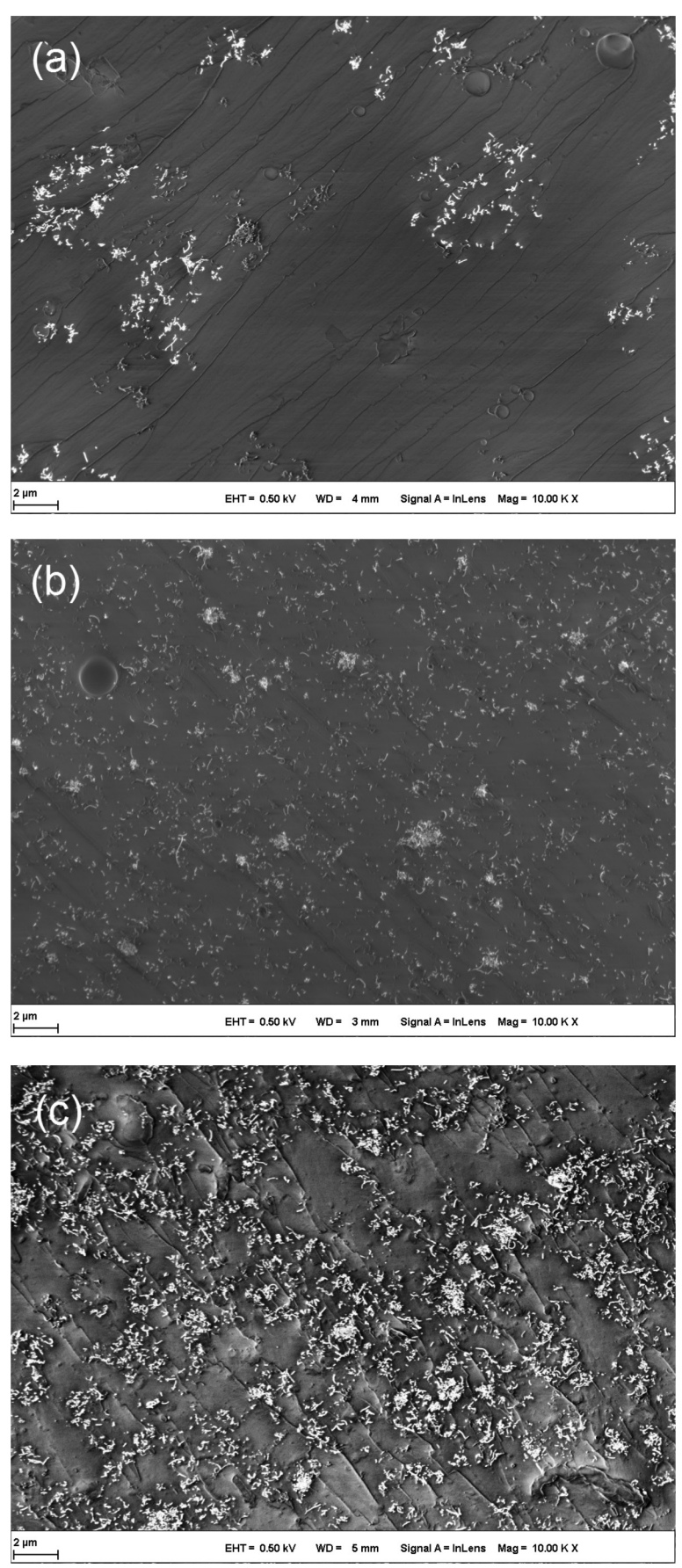

Figure 5. SEM micrographs obtained for fractured surfaces of CNT/ phenolic resin composites containing 0.5 wt. $\%$ of PSSS surfactant: (a) 0.1 wt. $\%$ CNT; (b) 0.5 wt. $\%$ CNT and (c) 1.0 wt.\% CNT. a given fraction of nanotubes under various conditions (sonication time, nanotube concentration, $\mathrm{pH}$, etc.). A minimum of SDS and PSSS surfactants to MWCNT in weight ratio is required to achieve dispersions with maximum achievable dispersion of CNT in aqueous solution.

The present results allow controlling the CNT dispersion into phenolic resin, by using CNT-dispersion. The SEM images of the CNT/phenolic resin fracture surfaces indicated a good dispersion of MWCNTs into the matrix, when at least a weight ratio surfactant/CNT of $0.5: 1$ is used.

The mechanical results (impact test) show an improved effect of the nanotubes for all tested volume loadings. This reinforcement seemed to be already effective at low filler contents (only $0.1 \mathrm{wt} . \%$ ) and reached the highest level for the present series at $1.0 \mathrm{wt} . \% \mathrm{CNT}$, when it is used both surfactants. Similar behavior happened in glass transition temperature. It was found a similar value when compared specimens obtained from PSSS and SDS surfactants.

\section{Acknowledgements}

The authors acknowledge financial support received from Fundação de Apoio a Pesquisa do Estado de São Paulo (FAPESP), under grant 2009/06335-9, and Conselho Nacional de Desenvolvimento Científico e Tecnológico (CNPq), under grant 306053/2006-3.

\section{References}

1. Grady, B. P.; Macromol. Rapid Commun. 2010, 31, 247.

2. Klier, J.; Tucker, C. J.; Kalantar, T. H.; Green, D. P.; Adv. Mater. 2000, 12, 1751.

3. Chen, G. X.; Kim, H. S.; Park, B. H.; Yoon, J.-S.; Polymer 2006, 47, 4760 .

4. Sengupta, R.; Ganguly, A.; Sabharwal, S.; Chak, T. K.; Bhowmick, A. K.; J. Mater. Sci. 2007, 42, 923.

5. Kang, M.; Myung, S. J.; Jin, H.-J.; Polymer 2006, 47, 3966.

6. Bose, S.; Rupesh, A.; Khare, R. A.; Moldenaers, P.; Polymer 2010, 51, 975.

7. Spitalsky, Z.; Tasis, D.; Papagelis, K.; Galiotis, C.; Prog. Polym. Sci. 2010, 35, 357. 
8. Tai, N. H.; Yeh, M. K.; Liu, J. H.; Carbon 2004, 42, 2774.

9. Yang, J.; Xu, T.; Zhang, Q.; Lu, A.; Fu, Q.; J. Appl. Polym. Sci. 2008, 109, 720.

10. Kotsilkova, R.; Ivanov, E.; Krustevo, E.; Silvestre, C.; Ciminino, S.; Duraccio, D.; J. Appl. Polym. Sci. 2010, 115, 3576.

11. Díez-Pascual, A. M.; Naffakh, M.; Gómes, M. A.; Marao, C.; Ellis, G.; Martinez, M. T.; Carbon 2009, 47, 3079.

12. Matarredona, O.; Rhoads, H.; Li, Z.; Harwell, J. H.; Balzano, L.; Resasco, D. E.; J. Phys. Chem. B 2003, 107, 13357.

13. Mathur, R. B.; Singh, B. P.; Dhami, T. L.; Kalra, Y.; Lal, N.; Polym. Compos. 2010, 31, 321.

14. Natali, M.; Kenny, J.; Torre, L.; Compos. Sci. Technol. 2010 , $70,571$.

15. Abdalla, M.; Dean, D.; Adibempe, D.; Nyciro, E.; Robinson, P.; Thompson, G.; Polymer 2007, 48, 5662.

16. Mandzy, N.; Grulke, E.; Druffel, T.; Powder Technol. 2005, $160,121$.

17. Su, J.-W.; Hsu, C.-Y.; Fu, S.-J.; Guo, C.-H.; Lin, K.-J.; J. Chin. Chem. Soc. 2009, 56, 935.

18. Poyato, R.; Vasiliev, A. L.; Padture, N. P.; Tanaka, H.; Nishimura, T.; Nanotechnology 2006, 17, 1770.

19. Angelikopoulos, P.; Gromov, A.; Leen, A.; Nerushev, O.; Bock, H.; Campbel, E. E. B.; J. Phys. Chem. C 2010, 114, 2.

20. Visco, A.; Calabrese, L.; Milone, C.; J. Reinf. Plast. Compos. 2009, 28, 937.
21. Kayatin, M.; Davis, V. A.; Macromolecules 2009, 42, 6624.

22. Nakashima, N.; Tomonari, Y.; Murakami, H.; Chem. Lett. 2002, 18,638 .

23. Yang, D.-Q.; Roquette, J.-F.; Sacher, E. J.; J. Phys. Chem. B 2005, 109, 7788 .

24. Krause, B.; Petzold, G.; Pegel, S.; Pötschke, P.; Carbon 2009, 47,602 .

25. Vaisman, L.; Wagner, H. D.; Marom, G.; Adv. Colloid Interface Sci. 2006, 128, 37.

26. Moore, V. C.; Strano, M. S.; Haroz, E. H.; Hauge, R. H.; Smalley, R. E.; Nano Letters 2003, 3, 1379.

27. Yu, J.; Grossiord, N.; Koning, C. E.; Loos, J.; Carbon 2007, 45,618 .

28. Xin, X.; Xu, G.; Zhao, T.; Zhu, Y.; Shi, X.; Gong, H.; Zhang, Z; J. Phys. Chem. C 2008, 112, 16377.

29. Hilding, J.; Grulke, E.; Zhang, Z. G.; Lockwood, F.; J. Dispersion Sci. Technol. 2003, 24, 1.

30. Tao, K.; Yang, S.; Grunlan, J. C.; Kim, B.; Dang, Y. S.; Deng, Y.; Thomas, R. L.; Wilson, B. L.; Wei, X.; J. Appl. Polym. Sci. 2006, 102, 5248 .

Submitted: March 29, 2011

Published online: August 25, 2011

FAPESP has sponsored the publication of this article. 